\title{
SURVEYING WORLD HERITAGE ISLAMIC MONUMENTS IN NORTH AFRICA: EXPERIENCES WITH SIMPLE PHOTOGRAMMETRIC TOOLS AND NO PREVIOUS PLANNING
}

\author{
A. Almagro \\ Escuela de Estudios Árabes, Spanish Council for Scientific Research (CSIC), Granada. Spain \\ aalmagro@eea.csic.es
}

KEY WORDS: Islamic architecture, World Heritage, photogrammetry, simple tools, 3x3 rules.

\begin{abstract}
:
Different experiences of surveys of Islamic monuments from different sites of Tunisia, Algeria and Morocco are presented. They have been made with simple tools: one photographic camera and a laser meter, without a previous planning or prevision for the survey, profiting from visits organized during scientific meetings to which the author was invited. Some of these monuments belong to sites included in the World Heritage List, but no metric documents or only low quality information is available. Monumental Almohad gates from Rabat and Marrakech, the al-Badi palace of Marrakech, the minarets of Mansura and the Qala of Beni Hammad, the dome in front of the mihrab of the mosque of Tlemcen are some of the examples to be presented.

The methodology applied is based on ideas and tools acquired in CIPA meetings proving the usefulness of these encounters but supporting the idea that "providers" should provide tools and methods and "users" should be responsible for documentation, never missing the opportunity of acquiring knowledge from the heritage during the survey process.
\end{abstract}

\section{INTRODUCTION}

The need for having good heritage documentation, especially in emerging or developing countries is being stressed during the political events that have occurred recently in the South and East Mediterranean areas, like the so call Arab Spring and the Syrian civil war. The destruction of cultural heritage, which sometimes are direct targets and other times collateral damage, deprives not only the involved societies but all of humanity from irreplaceable historical and cultural values. This is always an irreparable loss, which may only be minimally alleviated if at least there is a documentary record. When destruction is only partial, the documentation can make the restoration easier.

Unfortunately, in many of these countries the availability of proper documentation is very limited, especially metric, because of the difficulties involved in its elaboration. As a general rule, only technical drawings are made when restoration intervention is planned, and yet do not always have adequate quality. The need for valid and useful documentation is therefore evident and should constitute a priority action.

For years, the experience implemented at international level and shown, among other places, in the CIPA Symposia offers interesting solutions that allow us to glimpse the possibility of responding, at least partially, to the problem. We will show in this paper a number of experiences of surveys conducted on architectural heritage of Islamic origin in several countries of North Africa, mostly pertaining to property inscribed on the World Heritage List.

\section{INSTRUMENTS AND METHODOLOGY}

These case study surveys have a common set of circumstances that are of interest as experiences using a methodological approach for the urgent documentation of the heritage of countries as the above mentioned. First, they have been carried out with- out advance planning and therefore without a previous study of the building and its characteristics, which proves the versatility of the systems used and their easy adaptation to different circumstances. In all of these cases the purpose of the visit to the monument or site was not to perform documentation but simply a visit for a rapid architectural analysis of the buildings. Secondly, the instrumentation used in data collection has been extremely simple, in the majority of the cases a simple camera and an instrument for measuring, usually a Leica Disto. These are easy to transport and relatively inexpensive, not much more than what a typical tourist carries on. In some cases, the documentation was captured in such a discrete fashion that it was not evident that a survey was underway, which occasionally may be convenient to avoid suspicion.

Finally, the laboratory instrumentation is also relatively simple. The different case studies that are presented also show the evolution of the technology over time while the methodology can be considered unchanged. In the first example analytical plot-

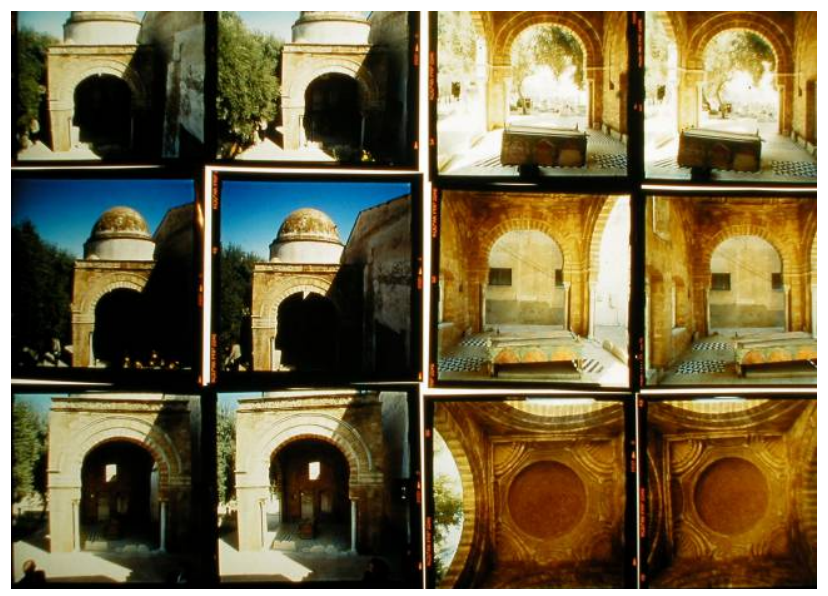

Figure 1. Set of photos used in the survey of the Qoubba Bou Khrissane in the Madina of Tunis 
ters were used with very sophisticated software and complex management. Fortunately, for the most recent cases the instrumentation was not only less expensive but much simpler to use thanks to the improvement of software and the use of digital photos.

In 1995, the survey of the qoubba Bou Khrissane of Tunis was carried out with a Hasselblad SWC semi-metric camera with reseau plate, calibrated by CSIC, a Leica SD 2000 plotter and software Leica MAAS-CR. A decade later the survey of the Almohad gates of Rabat and Marrakech were made with digital cameras Nikon Coolpix of 2 and 5 Mpixels and were plotted with the VSD software. For the latest works of the palace alBadi of Marrakech (2005) and in Tlemcen and the Qala of Beni Hammad (2012) a 10 Mpixel Ricoh GRD and Canon-SLR of 8 and 22 Mpixels cameras were used. The software Orthoware (Martos et alli 2008) from Metria (http://metria.es) was used for the orientation of the blocks of photos, PoivilliersF and ASRix for the stereoscopic restitution and for photo-rectification. As it can be seen, the software used has been developed by individuals or groups strongly linked with CIPA, which has served as a vehicle of transmission of knowledge and experience.

The methodology followed is based on the use of Photogrammetry as ideal means to acquire large amounts of information quickly and easily. The use of digital photogrammetry allows greatly reduced instrument cost. Three restitution systems were used. Bundle adjustment of blocks of photographs, whose first principles are known from late Prof. Wester-Ebinghaus in CIPA (Kotowski et alli. 1988), allows the simplified acquisition of control data, even dispensing with the use of topographic instruments. ORIENT (Kager 1980) and MAAS-CR constituted the first software that was used, but Orthoware software now appears very versatile, reliable and user friendly, as it allows working on the measurement and the computation interactively, rather than deferred, as in older programs. The principles to operate with this procedure have been systematized and disseminated by Prof. Waldhäusl with the $3 \times 3$ rules (Waldhäusl \& Ougleby 1994) that were basically followed, although not always with the thoroughness presented due to time limitations. Through a set of photographs and a few simple measurements and observations of the object (some distances between visible points and references of planes or lines that can be considered vertical or horizontal) a set of points was obtained with threedimensional coordinates in an established local coordinate system.

The orientation of the images block using a reduced control can raise doubts about the accuracy achieved, by the absence of check data. However, verification and calibration were tested in other projects. Recently the procedure was used to document and survey the main tower of the castle of Villena (Alicante, Spain), a building with square plan of $14 \mathrm{~m}$ side and $30 \mathrm{~m}$ of height. In addition to the photographs a number of points were measured with a total station with laser EDM (Electronic Distance Measure). In the absolute orientation of the block a first test was performed using only the distance between two points and the consideration that an impost that runs along the facades defines an horizontal plane. The result was fully valid in relationn to the size, shape and overall dimensions of the tower. The impost, however, is not perfectly horizontal, as on one side there is a difference in level of $5 \mathrm{~cm}$ which introduced minor errors of absolute position of the measured points resulting in maximum discrepancy of $6 \mathrm{~cm}$. Using three control points measured with the total station for comparison, the maximum discrepancies between the measurements and those made with
Orthoware were only $3 \mathrm{~cm}$ which proves the reliability of the system, demonstrating that work can be rapidly conducted without the use of surveying instruments with perfectly valid results for most purposes for which these surveys are used.

Final graphic documents, which essentially are vector drawings, were obtained in most cases through stereoscopic restitution. This procedure allows an observation and analysis of the object very close to that achieved with direct vision, enabling selection and synthesis during drawing for excellent condition results and with remarkable speed. We have always defended the importance that this process has for a better knowledge of the building or object that is being documented, which constitutes the ultimate goal of all survey (Almagro and Almagro-Vidal 2007). Today the use of the analytical plotter SD2000 continues, although almost all the works shown here have been made with VSD of AGH (Jachimski 1995) and increased use of the software PoivilliersF. The latter, developed by Yves Egels, is a very simple and easy to use software, which works in two modes: with anaglyph glasses for simpler hardware (laptops) or 3D glasses like NVDIA 3D Vision, today easily accessible thanks to the development of 3D computer games.

When more information needs to be introduced such as textures and details photographic rectification software is used for all the elements that exist in a flat plane, very frequent case in architecture. The software, ASRix by Steve Nickerson, allows photos to be entered directly into AutoCad 3D drawings in a simple and accurate way. The instruments exist and are easily affordable, not only for a Government Office, but for an independent professional. It is only required to know how to use them and for this reason training is needed, and thus should be emphasized as a priority.

\section{CASE STUDIES}

The case studies range across North Africa from Tunisia to Morocco and Algeria. They were selected as they represent the full versatility of the methodology presented here and the evolution of the techniques available at that time. Tunis, Marrakech, Rabat and the Qala of Beni Hammad are inscribed in the World Heritage List.

Qoubba Bou Khrissane, Medina of Tunis, Tunisia. This funerary dome of the $11^{\text {th }}$ century, located in the Medina of Tunis was the subject of a practical case study in the Course of Tunis
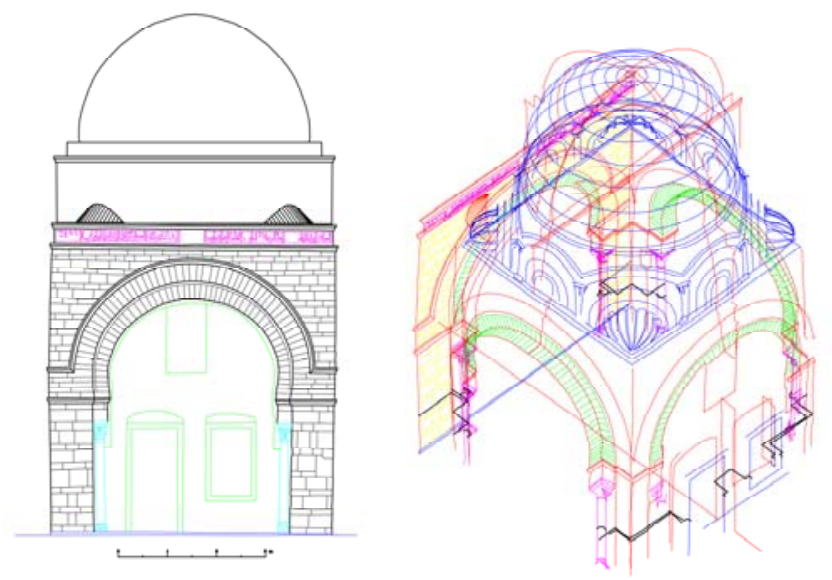

Figure 2. Elevation and 3D model of the Qoubba Bou Khrissane in Tunis 
For restoration technicians. Through 12 photographs (6 stereoscopic pairs), two distances and the reference of an horizontal line traced on two interior faces, a plan with the projection of the dome, two sections and an elevation were plotted. All of these drawings create together a 3D model.

Bab Agnau. Marrakech. Morocco. The most monumental of the Almohad gates of Marrakech was plotted, in 2001, from two stereo pairs of digital photos of 2 Mpixel. One stereo pair was captured from farther away for drawing the whole facade and another closer for drawing the decoration and details, which were oriented using points measured from the distant pair to establish adequate concordance between the two models. Two distances, a horizontal and a vertical measured with tape were used. The same façade was used as a reference for a vertical plane and the cornice as a horizontal reference line.

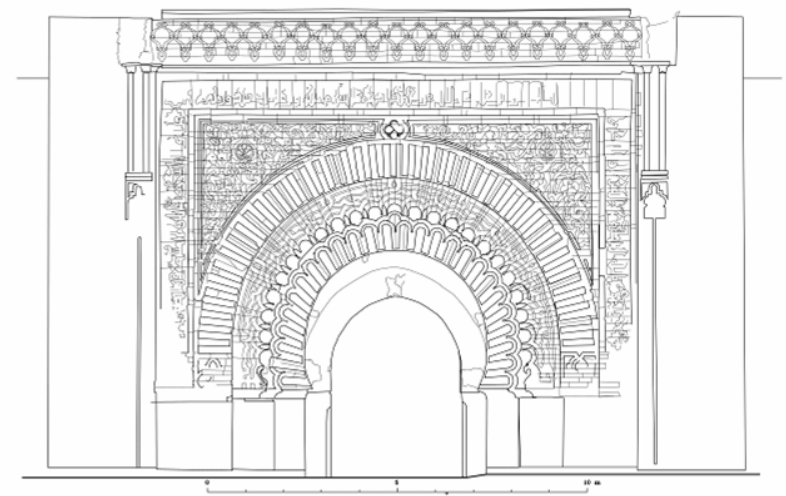

Figure 3. Elevation of Bab Agnau in Marrakech

Bab al-Kebir. Kasbah of Rabat. Morocco. The gate of the Almohad Kasbah of Rabat is a building of imposing appearance with two monumental portals, one outward and one inward, richly decorated. As in the previous case three pairs of photos were taken, one for each façade, with a 5 Mpixel camera, as well as a distance on each side. The references to the external orientation were taken from the building itself: the vertical plane of the facade and a horizontal line of the ornamental framing. The use of a camera with higher resolution avoided the use of detail photos.

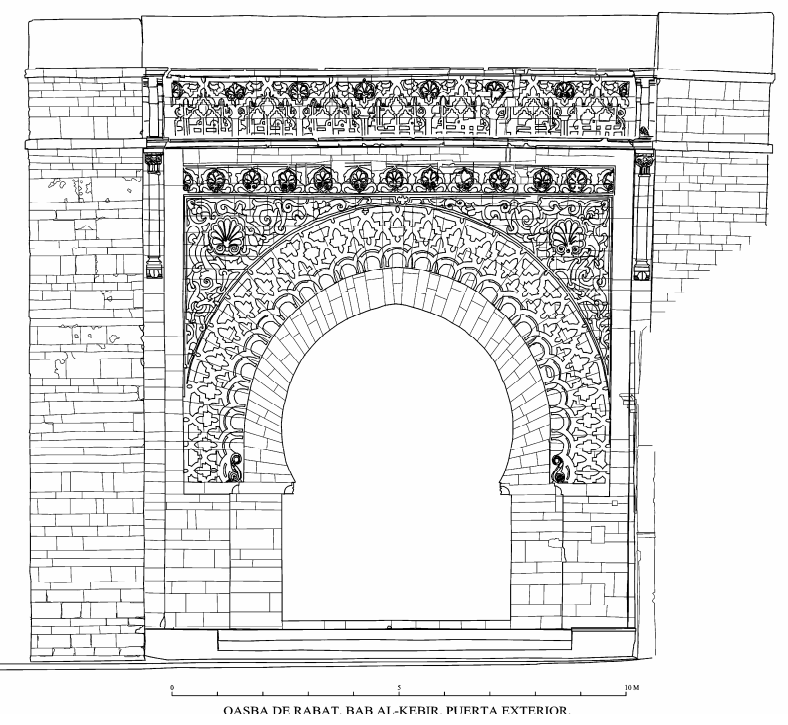

Figure 4. Elevation of the exterior gate of Bab al-Kebir in Rabat.

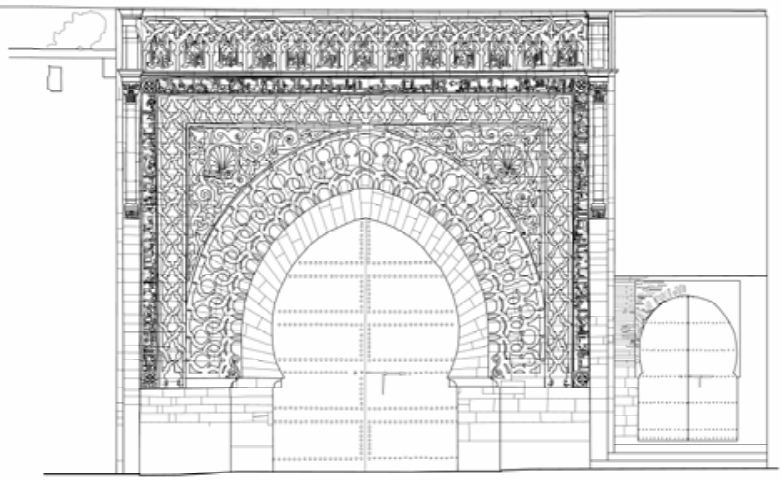

Figure 5. Elevation of the interior gate of Bab al-Kebir in Rabat

Al-Badi Palace, Marrakech. Morocco. Various parts of the ruins of this imposing monument from the $16^{\text {th }}$ century were surveyed at two different times using 8 and 22 Mpixels cameras. This includes the Western Pavilion of the courtyard and the North Hall of the Palace. The existence of large openings between the inside and outside allowed successful linking of the external photos with those of the interior rooms by common points for the orientation of the blocks of photographs. Therefore other complementary photos were not needed but only the stereo pairs. Eight photos of interior and six from the outside (7 pairs) were used for the Western Pavilion, while in the North Hall 8 pairs of internal and one external were needed. Vector drawings of every wall were plotted and by joining the different files it was possible to obtain, in both cases, a 3D model of the whole structure. The analysis of the walls during the restitution process has allowed a reconstruction proposal of the form and decoration of these spaces which has resulted in different images and virtual reality tours.

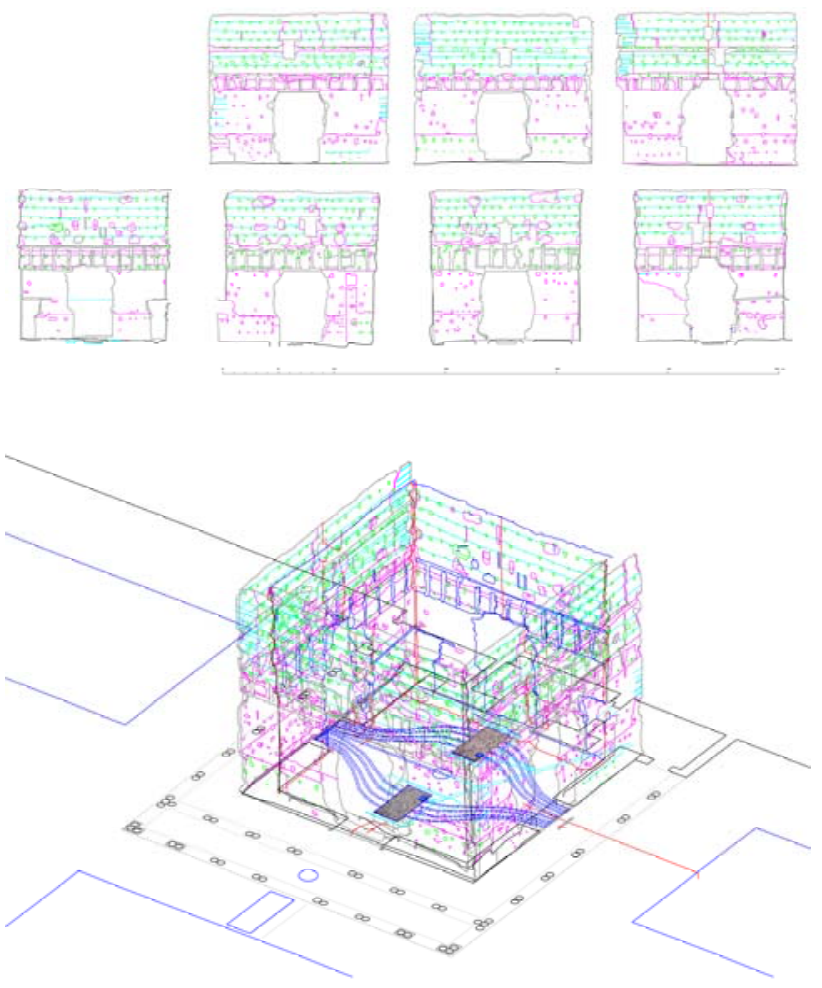

Figure 6. Elevations and 3D model of the western pavillion of al-Badi palace in Marrakech. 


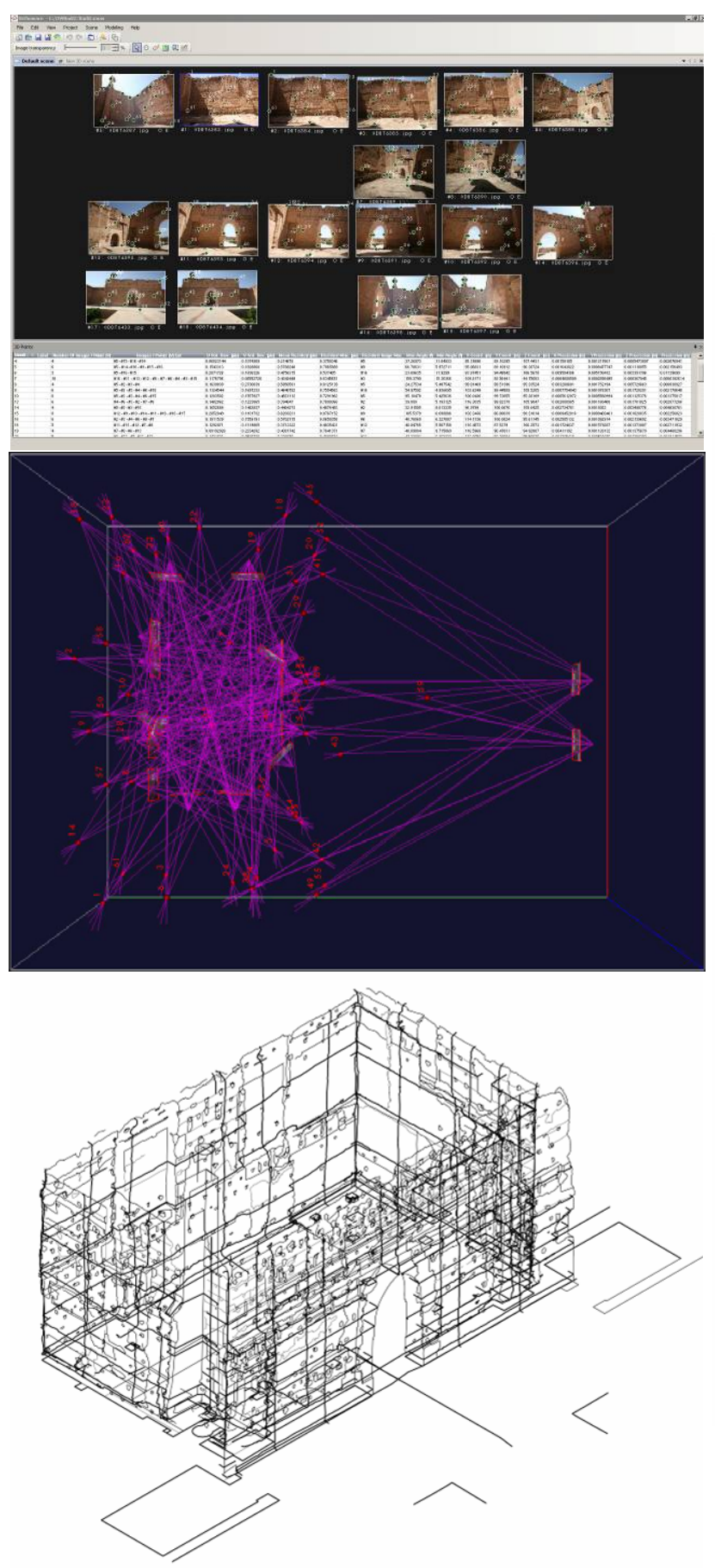

Figure 7. Block of photos, bundle adjustment and 3D model of the North hall of the palace al-Badi in Marrakech.

Dome in front of the mihrab in the mosque of Tlemcen, Algeria. This masterpiece of the Almoravid art from the end of the $11^{\text {th }}$ century lacked a metric survey, despite having been studied and published in numerous scientific books and publications. The documentation work was one of the most complexes, since when the photos were obtained the goal was not orienting a complete block, but only separate stereo-pairs to plot some building elements. After obtaining more advanced software, it was possible to make the full suvey and this has allowed the creation of a 3D model of the space beside the mihrab. In this case, the absolute orientation was made considering that the cornice where the dome is supported defines a horizontal plane.
Fifteen pictures were used for the block and 4 pairs for the restitution of the drawings. The photogrammetric survey was completed with manual measurements of areas which could not be recorded with photographs, such as the space between the dome and the roof. The façade of the prayer room into the courtyard of the mosque was also plotted and the next step will be to complete the survey of the minaret.

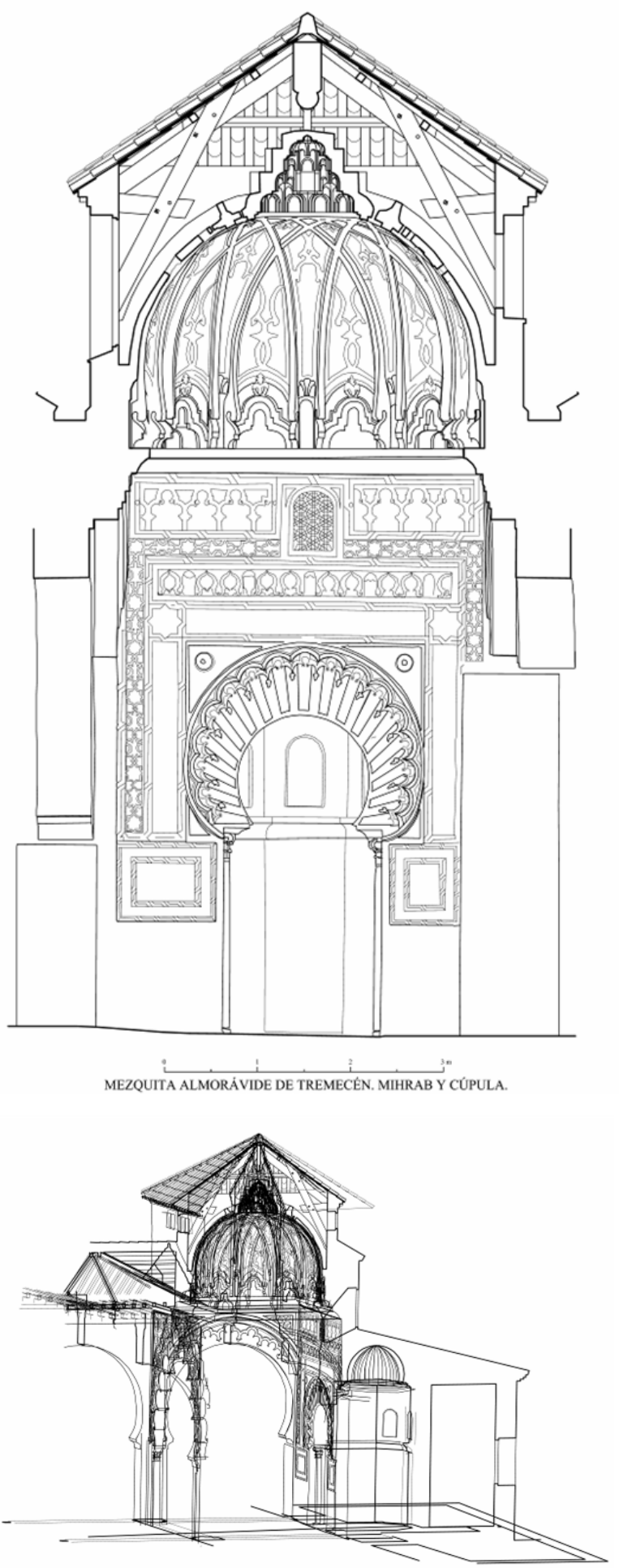

Figure 8. Cross section and 3D model of the dome beside the mihrab of the great mosque of Tlemcen 
Minaret of Mansura. Tlemcen. Algeria.

This tower of $10 \mathrm{~m}$ square and $40 \mathrm{~m}$ in height was built by the Marinids in the $14^{\text {th }}$ century and represents an exemplary case for this type of survey. Currently an isolated building, pictures were taken all around with stereoscopic pairs and oblique photos at angles to unite the facades. Four stereoscopic pairs and five oblique photos were captured. The orientation of the block and the stereoscopic restitution were performed by Sara Morena, a student in her final year at the school of architecture of Salerno (Italy), who did a three month stage in our Institute within the program Erasmus-practice, and despite having no previous experience in the use of the software or stereoscopic restitution, she could complete the documentation during her stay. The work that is shown here is a demonstration of how sufficient skills can be achieved in the use of these techniques in a short period of time. The four faces of the tower have been plotted resulting in the corresponding 3D model.
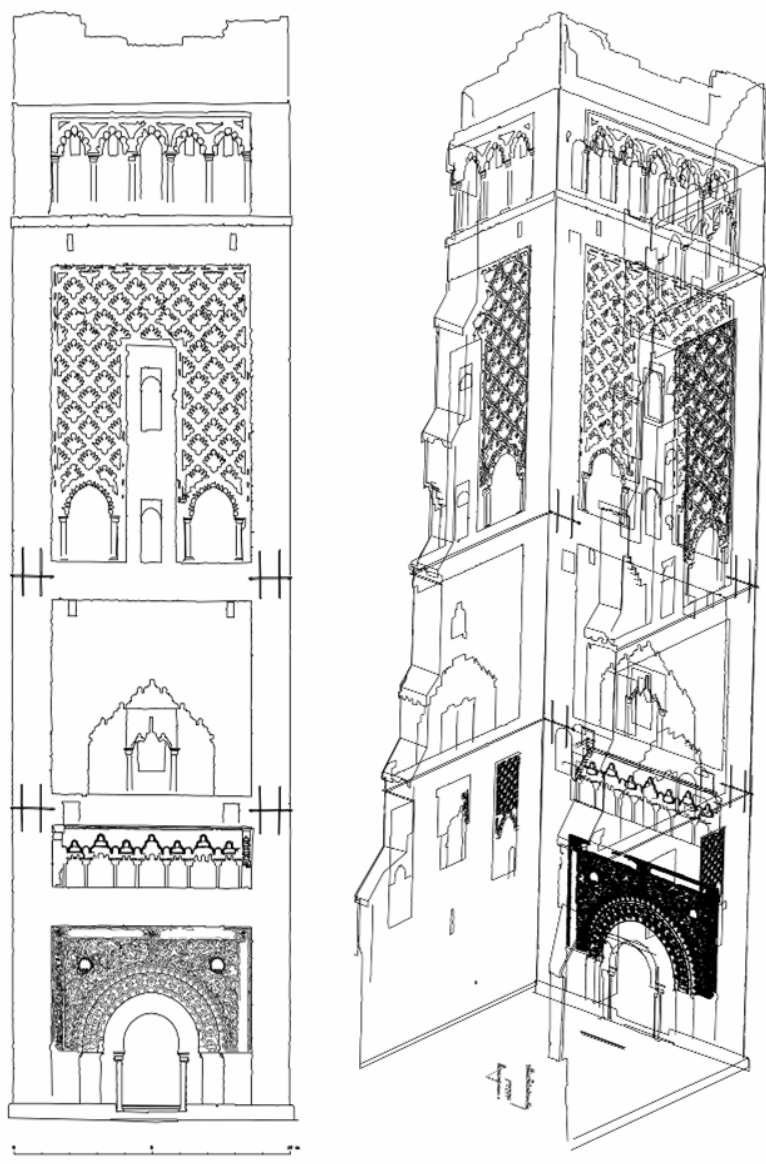

Figure 9. Elevation and 3D model of the minaret of Mansura

Minaret in the Qala of Beni Hammad, Algeria. This archaeological site from the 11th century, inscribed on the World Heritage list contains the remains of an interesting minaret. The survey was made with four stereoscopic pairs and four oblique photographs for linking the facades and a distance of height taken from one of the openings of the facade to the ground. The survey includes the vector drawings of the four elevations and the corresponding photo-rectification showing the detail of the masonry. A comparison was made with an old survey published by the French scholar L. Golvin (Golvin 1957: 185). This shows a significant magnitude of the error in the height of the tower from that drawing, of more than $1.5 \mathrm{~m}$. This is the only documentation that previously existed for this important cultural property and demonstrates the lack of the appropriate accuracy.

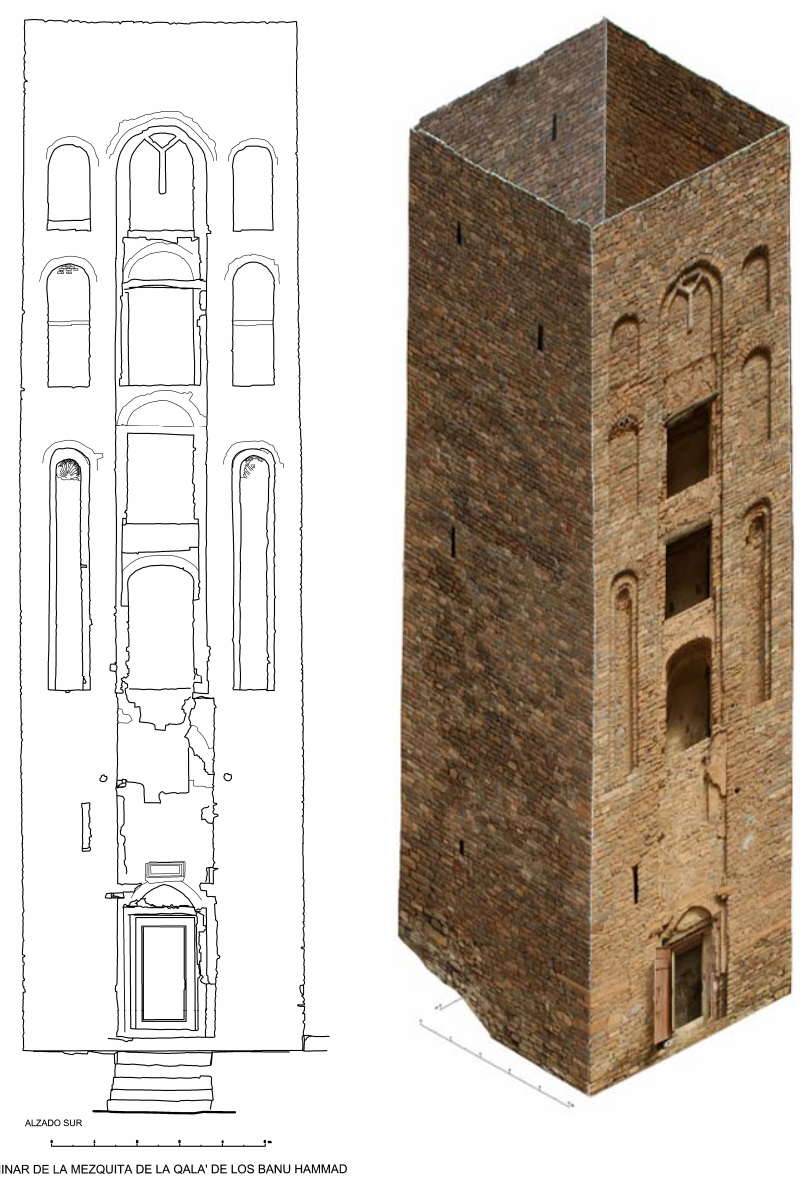

Figure 10. Elevation and photographic 3D model of the minaret of the Qala of Beni Hammad

\section{CONCLUSIONS}

The experiences presented here constitute good examples of the possibilities offered by Photogrammetry with the current state of the art of this technique; the instruments and software are fairly low cost and easy to use so they can be learned without too much difficulty by anyone who already possesses basic knowledge on forms and modes of representing historic architecture. It is more difficult to learn the nature, characteristics and importance of architectural elements than the photogrammetric documentation technology. To understand and thus properly document cultural heritage requires basic manual drawing skills, a capacity for synthesis and an understanding of history, values and artistic styles. Attempting to circumvent this knowledge by using automated systems can result in serious deficiencies in the quality of the surveys.

The limits for these systems are related to the size of the building and thus, with the quality (detail and resolution) of the pictures we can obtain, and finally, with the possibility of geting pictures according to the $3 \times 3$ rules. A characteristic case like a tower that can be photographed from the four sides and the four corners could be performed easily by people without much experience. More complex cases like the ones with interior and exterior areas and limited links between them should need more 
experience specially to solve problems when the orientation does not converge at the first try. Even if we do not have any experience yet with very large and complex buildings, we estimate that in such cases a basic control survey with topographic instruments will be needed to avoid too large errors.

In any case, the improvement and dissemination of these systems and methodologies should be a priority in order to provide managers and technicians involved in the conservation of cultural heritage appropriate instruments for documentation. This is especially true in those places where the social and political circumstances threaten the conservation of a heritage of incalculable value.

\section{References}

Almagro, A., Almagro-Vidal, A., 2007, “Traditional drawings versus new representation techniques”, Proceedings of the 21st CIPA International Syposium: Anticipating the Future of the Cultural Past, Athens, pp. 52-57.

Golvin, L., 1957, Le Magrib Central à l'Époque des Zirides, Paris.

Jachimski, J., 1995, "Video Stereo Digitizer. A small digital stereophotogrammetric working station for the needs of sit and other application”, Geodesy, Photogrammetry and Monitoring of Environment (Chosen Problems), Geodezja, 38, pp. 71-93.
Martos A., Navarro S., Lerma J.L., Rodríguez S., Rodríguez J., 2008, "Orthoware: Software Tool for Image Based Architectural Photogrammetry", Proceedings of the14th International Conference on Virtual Systems and Multimedia. Cyprus.

Nickerson, S., Chapiro, A., 2005, "ASRix: A Simple Image Rectifier”, CIPA 2005, XX International Symposium. International Cooperation to Save the World Cultural Heritage. Torino 21 September -1 October 2005. vol 1. Torino, pp. 476-480. http://www.asrix.ca.

Waldhäusl, P., Ougleby, C. L.,1994, “3x3 Rules for Simple Photogrammetric Documentation of Architecture", International Archives of Photogrammetry and Remote Sensing, XXX5, Melbourne, pp. 426-429.

Kager, H., 1980, Das interaktive Programmsystem Orient im Einsatz. International Archives of Photogrammetry, 23(B5), pp. 390-401.

Kotowski, R., Peipe, J., Wester-Ebbinghaus, W. 1988, Bundle Triangulation in Architectural Photogrammetry: The Basilica of San Francesco in Siena, Photogrammetric Record, 12 (72), pp. 857-871.

\section{Acknowledgements}

I thank Rand Eppich for his suggestions and for reading and correcting the English text, and all those who gave me the opportunity for visiting all these monuments.

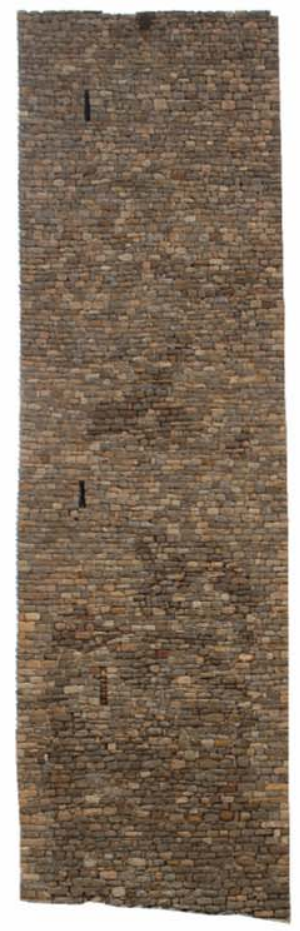

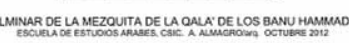
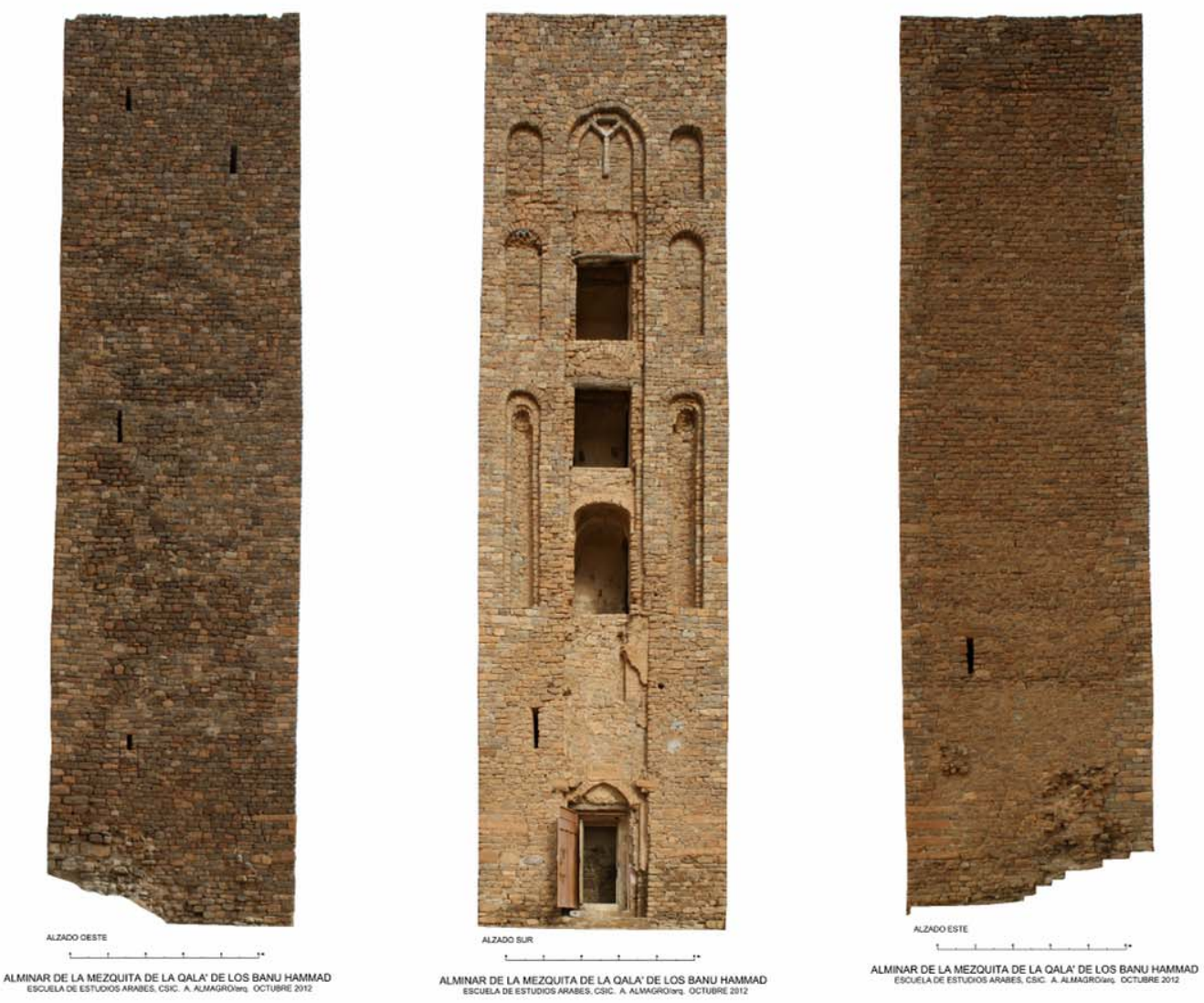

Figure 11. Photo rectifications of the façades of the minaret of the Qala of Beni Hammad. Algeria 